\title{
Desempenho e Características de Carcaça de Coelhos Alimentados com Rações Contendo Diferentes Níveis de Amido e Fontes de Fibra ${ }^{1}$
}

\author{
Alex Martins Varela de Arruda ${ }^{2}$, Darci Clementino Lopes ${ }^{3}$, Walter Motta Ferreira ${ }^{4}$, \\ Horacio Santiago Rostagno ${ }^{3}$, Augusto César de Queiroz ${ }^{3}$, Elzânia Sales Pereira², \\ Aloízio Soares Ferreira ${ }^{3}$, José Francisco da Silva ${ }^{3}$
}

\begin{abstract}
RESUMO - O objetivo do presente estudo foi avaliar o desempenho e as características quantitativas e qualitativas da carcaça de coelhos em crescimento alimentados com rações contendo diferentes níveis de amido (22 e 32\% em média) mediante a inclusão de milho grão e diferentes fontes de fibra (feno de alfafa ou casca de soja), em esquema fatorial 2x2. As rações experimentais foram peletizadas e fornecidas à vontade durante um período de 40 dias, para 40 coelhos desmamados aos 35 dias, alojados individualmente e seguindo delineamento inteiramente casualizado. Não foram observados efeitos significativos para a interação entre fonte de fibra e nível de amido sobre os parâmetros avaliados neste estudo. O consumo de alimento foi maior para as rações contendo feno de alfafa (91,27 g/d), mas ganho de peso e conversão alimentar não diferiram estatisticamente entre os tratamentos (média geral de 30,18 g/d e 2,94). O rendimento, teor de proteína, a eficiência protéica e energética de carcaça foram melhores com as rações contendo maiores níveis de amido (50,20; 62,36; 56,38; e 30,04\%, respectivamente), mas não diferiram estatisticamente para as fontes de fibra. Assim, rações contendo maiores níveis de amido ou contendo casca de soja propiciaram melhores índices de conversão alimentar e melhores características de carcaça, possivelmente, reflexo de melhor eficiência de utilização dos nutrientes.
\end{abstract}

Palavras-chave: carcaça, casca de soja, coelhos, desempenho, feno de alfafa, milho grão

\section{Performance and Carcass Characteristics of Rabbits Fed Diets with Different Starch Levels and Fiber Sources}

\begin{abstract}
The objective of the present study were evaluated the performance, quantitative and qualitative characteristics of the carcass in growing rabbits feeding with diets contents different starch levels (22 or 32\% on average) by high or low inclusion of corn grain and different fiber sources (alfalfa hay or soybean hulls), in 2x2 factorial design. The experimental diets were pellets and fed ad libitum during 40 days to 40 rabbits weaned at 35 days, housed individually and assigned to a complete randomized design. Significant effects were not observed for the interaction between the fiber sources and the starch levels to the parameters evaluated in this study. Higher feed intake was observed with diets contents alfalfa hay (91.27 g/d), but the weight gain and food conversion were significant affected by the dietary treatments (30,18 g/d and 2.94 general average, respectively). The carcass yield, protein level, protein and energy efficiency in the carcass showed giher values for the diets with high starch levels (50.20, 62.36, 56.38 and 30.04\%, respectively). Diets with high starch level or with soybean hulls resulted in better indexes of food conversion and characteristics of the carcass, reflex of a better nutrients utilization efficiency.
\end{abstract}

Key Words: alfalfa hay, carcass, corn grain, nutrition, performance, rabbits, soybean hulls

\section{Introdução}

A maioria dos estudos objetivando avaliar as recomendações nutricionais e seus efeitos sobre o desempenho de coelhos na fase de crescimento, entre a desmama e o abate, visando a produção de carne, demonstra grande variabilidade na eficiência alimentar, apesar dos mesmos terem como referência na formulação de rações, níveis de 15 a $17 \%$ de proteína bruta e 2400 a 2700 kcal energia digestível/kg (NRC, 1977; INRA, 1984; Rhodimet, 1993; De Blas \& Wiseman, 1998; Lebas, 1999). A variação nos índices de produção deve-se, em grande parte, a diferenças na qualidade das matérias-primas utilizadas para o balanceamento de proteína, energia e fibra dietética, sendo o último, o principal fator de variação, visto que a inclusão de volumosos, visando atender a necessidade de fibra "indigestível", apresenta difícil padronização e possui efeitos determinantes sobre

\footnotetext{
${ }_{1}^{1}$ Parte da Tese de Doutorado do primeiro autor, financiado pela UFV e FAPEMIG

2 Professor do Curso de Zootecnia da UNIOESTE, Mal. Cândido Rondon - PR E.mail: amvarela@unioeste.br

3 Professor do Curso de Zootecnia da UFV, Viçosa - MG.

${ }^{4}$ Professor do Curso de Veterinária da UFMG, Belo Horizonte - MG.
} 
o aproveitamento de nutrientes e equilíbrio digestivo nestes animais (Ferreira, 1989).

Atualmente, na nutrição de coelhos, a estreita relação entre eficiência alimentar e sanidade do plantel na fase de crescimento, constitui-se fator limitante quando da inclusão de alimentos volumosos e cereais para elaboração de rações completas. Segundo Cheeke (1995), a microflora intestinal, o padrão fermentativo, motilidade do ceco-cólon, a dualidade da excreção fecal (cecotrofia) e o rendimento produtivo destes animais podem ser influenciados ao se alterar excessivamente a recomendação nutricional de fibra e amido, podendo atuar como agente permissivo aos distúrbios digestivos. A redução na proporção dietética entre fibra/amido, geralmente, promove redução no consumo, maior atividade fermentativa e, conseqüentemente, maior tempo de retenção em função da atividade antiperistáltica no ceco-cólon, induzida pelas pequenas partículas a serem destinadas ao ceco, que possivelmente, levam à disbiose microbiana, associada aos colibacilos e clostrídios subdominantes, principais agentes causadores de diarréias e enterotoxemias em coelhos, respectivamente(De Blas \& Wiseman, 1998; Gidenne, 1996). Portanto, não só a quantidade, mas também a qualidade da fibra incorporada na dieta, associada aos teores de amido, pode acarretar alterações na fisiologia digestiva nesta espécie.

Por outro lado, como os demais não-ruminantes, os coelhos regulam seu consumo de matéria seca e, conseqüentemente, o consumo de nutrientes através do nível energético das rações. Segundo Lleonart et al. (1980), Lang (1981), Cheeke (1987) e De Blas (1989), este ajuste fisiológico ocorre em uma amplitude de 2200 a $3200 \mathrm{kcal} \mathrm{ED/kg}$ de ração, sendo verificado para níveis muito inferiores que o aumento no consumo pode não ser suficiente para suprir a demanda energética do metabolismo animal, enquanto níveis muito superiores aumentam grandemente os riscos de enterites ou diarréias, especialmente na fase subseqüente ao desmame, devido ao sistema digestivo apresentar-se ainda em desenvolvimento e capacitação para o aproveitamento de nutrientes dos alimentos sólidos. Assim, sugeriu-se outra variabilidade dietética a ser potencialmente investigada, a substituição da inclusão maciça de cereais por óleos ou gorduras e alimentos fibrosos de maior degradabilidade cecal ou contendo frações menos lignificadas como fonte de energia (Lebas, 1992; Gidenne, 1996).
Nesse contexto, visando melhor entendimento e prevenção dos distúrbios digestivos, e ao mesmo tempo, procurando otimizar o rendimento produtivo nesta espécie, o presente estudo foi conduzido com o objetivo de avaliar a influência de diferentes níveis de amido e fontes de fibra em rações para coelhos da raça Nova Zelândia Branco em crescimento sobre o desempenho, em termos de consumo, ganho de peso, conversão alimentar, além do rendimento produtivo e características de carcaça na terminação destes animais.

\section{Material e Métodos}

O experimento foi conduzido no setor de Cunicultura, do Departamento de Zootecnia, do Centro de Ciências Agrárias, da Universidade Federal de Viçosa.

Para condução do experimento, foram utilizadas gaiolas individuais de arame galvanizado, com dimensões de $40 \mathrm{~cm}$ x $60 \mathrm{~cm}$ x $45 \mathrm{~cm}$, providas de bebedouros automáticos tipo chupeta e comedouro de chapa galvanizada semi-automático, instalados em um galpão de alvenaria com $6 \mathrm{~m}$ de largura, pé direito de $3 \mathrm{~m}$, cobertura de telha de amianto e muretas laterais providas de tela e cortinas de plástico para controle da ventilação. Diariamente, foi registrada a temperatura por meio de um termômetro de máxima e mínima, instalado à altura da gaiolas, sendo de 31 e $19^{\circ} \mathrm{C}$ a amplitude térmica média durante o período experimental.

Os tratamentos foram resultantes de dois níveis de amido (22 e 32\% em média) através da inclusão de milho grão moído nas rações e duas fontes de fibra (feno de alfafa ou casca de soja), ambas associadas com sabugo de milho, totalizando quatro rações experimentais. As amostras de alimento e das rações foram coletadas e moídas em moinho tipo Wiley, peneira de malha $1,0 \mathrm{~mm}$, e em seguida acondicionadas em recipientes plásticos identificados para as análises químicas realizadas no Laboratório de Nutrição Animal, no Departamento de Zootecnia, da Universidade Federal de Viçosa, conforme metodologia descrita pela AOAC (1990) e Van Soest et al. (1991). As rações foram elaboradas de forma a serem isoprotéicas e isocalóricas, sendo também peletizadas, levando-se em consideração as exigências nutricionais dos coelhos em fase de crescimento, segundo o INRA (1984) e Lebas et al. (1986). A composição percentual e química das rações experimentais que constituíram os tratamentos dietéticos encontra-se nas Tabelas 1 e 2 , respectivamente. 
Tabela 1 - Composição percentual das rações experimentais

Table 1 - Percentual composition of the experimental diets

\begin{tabular}{|c|c|c|c|c|}
\hline \multirow[b]{2}{*}{$\begin{array}{l}\text { Ingredientes } \\
\text { Ingredients }\end{array}$} & \multicolumn{4}{|c|}{$\begin{array}{l}\text { Tratamentos dietéticos } \\
\text { Dietary treatments }\end{array}$} \\
\hline & $\begin{array}{c}\text { Alto amido c/ feno } \\
\text { de alfafa AAFA }{ }^{1} \\
\text { (high starch, } \\
\text { alfalfa hay) }\end{array}$ & $\begin{array}{c}\text { Alto amido c/ casca } \\
\text { de soja AACS } \\
\text { (high starch, } \\
\text { soybean hulls) }\end{array}$ & $\begin{array}{c}\text { Baixo amido c/ feno } \\
\text { de alfafa BAFA }{ }^{3} \\
\text { (low starch, } \\
\text { alfalfa hay) }\end{array}$ & $\begin{array}{c}\text { Baixo amido c/ casca } \\
\text { de soja BACS } \\
\text { (low starch, } \\
\text { soybean hulls) }\end{array}$ \\
\hline Milho grão moído & 46,0 & 47,5 & 28,0 & 30,0 \\
\hline $\begin{array}{l}\text { Ground corn grain } \\
\text { Feno de alfafa } \\
\text { Alfalfa hay }\end{array}$ & 20,0 & - & 35,0 & - \\
\hline $\begin{array}{l}\text { Casca de soja } \\
\text { Soybean hulls }\end{array}$ & - & 15,0 & - & 25,0 \\
\hline $\begin{array}{l}\text { Óleo de soja } \\
\text { Soybean oil }\end{array}$ & - & - & 4,60 & 5,00 \\
\hline $\begin{array}{l}\text { Farelo de soja } \\
\text { Soybean oil }\end{array}$ & 16,0 & 20,0 & 13,5 & 20,7 \\
\hline $\begin{array}{l}\text { Farelo de trigo } \\
\text { Wheat bran }\end{array}$ & 9,00 & 9,00 & 9,00 & 9,00 \\
\hline $\begin{array}{l}\text { Sabugo milho } \\
\text { Ground corn cob }\end{array}$ & 6,00 & 5,00 & 6,00 & 5,00 \\
\hline $\begin{array}{l}\text { Sal comum } \\
\text { Salt }\end{array}$ & 0,60 & 0,60 & 0,60 & 0,60 \\
\hline $\begin{array}{l}\text { Calcário } \\
\text { Limestone }\end{array}$ & 0,60 & 1,10 & 0,05 & 0,85 \\
\hline $\begin{array}{l}\text { Fosfato bicálcico } \\
\text { Dicalcium phosphate }\end{array}$ & 1,00 & 0,90 & 1,20 & 1,10 \\
\hline $\begin{array}{l}\text { Suplem. Min. Vit. } \\
\text { Mineral and vitamin premix }\end{array}$ & 0,40 & 0,40 & 0,40 & 0,40 \\
\hline $\begin{array}{l}\text { DL-metionina } \\
\text { Dl methionine }\end{array}$ & 0,05 & 0,05 & 0,10 & 0,10 \\
\hline $\begin{array}{l}\text { L-lisina } \\
\text { L-lysine }\end{array}$ & 0,10 & 0,04 & 0,09 & 0,02 \\
\hline $\begin{array}{l}\text { Caulim } \\
\text { Caulin }\end{array}$ & 0,25 & 0,41 & 1,46 & 2,23 \\
\hline Total (kg) & 100 & 100 & 100 & 100 \\
\hline
\end{tabular}

Para avaliar a influência das rações experimentais sobre o desempenho, rendimento e características de carcaça, por intermédio de esquema fatorial (2x2) seguindo delineamento inteiramente casualizado, foram utilizados 40 coelhos da raça Nova Zelândia Branco, de ambos os sexos, desmamados aos 35 dias de idade, previamente uniformizados com base no peso vivo, e então alojados individualmente e distribuídos aleatoriamente aos tratamentos. O período de adaptação foi de 10 dias e o período experimental, de 40 dias, sendo feita a pesagem dos animais ao início e ao final deste período (45 e 85 dias de idade), quando foram abatidos. Os animais receberam água e alimento à vontade, determinando-se desta forma consumo, ganho de peso e conversão alimentar. Os coelhos foram abatidos por atordoamento e sangria na jugular, procedendo-se à retirada da cabeça, patas, cauda, pele e a evisceração completa, higienização e pesagem a quente para obter o rendimento de carcaça (Arruda, 1997).

Em seguida, as carcaças foram guardadas individualmente em sacos plásticos identificados e armazenados em câmara fria, posteriormente, trituradas em "cutter" comercial de 30HP (1800 rpm), homogeneizadas e retiradas amostras, as quais foram armazenadas em freezer a $-10^{\circ} \mathrm{C}$. No preparo das amostras de carcaça para análise de matéria seca, proteína, extrato etéreo e energia (Silva, 1990), foi necessário realizar uma pré-secagem do material em estufa de ventilação forçada a $70^{\circ} \mathrm{C}$, por 36 horas, e 
Tabela 2 - Composição química das rações experimentais (base da MS) Table 2 - Chemical composition of the experimental diets (dry matter basis)

\begin{tabular}{|c|c|c|c|c|}
\hline \multirow[b]{2}{*}{$\begin{array}{l}\text { Ingredientes } \\
\text { Ingredients }\end{array}$} & \multicolumn{4}{|c|}{$\begin{array}{l}\text { Tratamentos dietéticos } \\
\text { Dietary treatments }\end{array}$} \\
\hline & $\begin{array}{c}\text { Alto amido c/ feno } \\
\text { de alfafa AAFA }{ }^{1} \\
\text { (high starch, } \\
\text { alfalfa hay) }\end{array}$ & $\begin{array}{l}\text { Alto amido c/ casca } \\
\text { de soja AACS }{ }^{2} \\
\text { (high starch, } \\
\text { soybean hulls) }\end{array}$ & $\begin{array}{c}\text { Baixo amido c/ feno } \\
\text { de alfafa BAFA } \\
\text { (low starch, } \\
\text { alfalfa hay) }\end{array}$ & $\begin{array}{c}\text { Baixo amido c/ casca } \\
\text { de soja BACS } \\
\text { (low starch, } \\
\text { soybean hulls) }\end{array}$ \\
\hline $\begin{array}{l}\text { Amido \% } \\
\text { Starch }\end{array}$ & 31,91 & 32,81 & 21,57 & 22,68 \\
\hline Fibra det. neutro \% (NDF) & 24,47 & 23,23 & 30,31 & 28,92 \\
\hline Fibra det. ácido \% (ADF) & 14,04 & 14,43 & 18,18 & 18,68 \\
\hline $\begin{array}{l}\text { Lignina \% } \\
\text { Lignine }\end{array}$ & 4,00 & 2,80 & 5,90 & 3,70 \\
\hline $\begin{array}{l}\text { Extrato etéreo \% } \\
\text { Ether extract }\end{array}$ & 3,11 & 2,90 & 7,41 & 7,40 \\
\hline $\begin{array}{l}\text { Energia bruta kcal/kg } \\
\text { Gross energy }\end{array}$ & 4415 & 4281 & 4708 & 4597 \\
\hline $\begin{array}{l}\text { Energia digestível }{ }^{1} \mathrm{kcal} / \mathrm{kg} \\
\text { Digestible energy }\end{array}$ & 2723 & 2764 & 2583 & 2627 \\
\hline $\begin{array}{l}\text { Proteína bruta \% } \\
\text { Crude protein }\end{array}$ & 17,07 & 17,10 & 17,12 & 17,09 \\
\hline $\begin{array}{l}\text { Proteína digestível }{ }^{1} \% \\
\text { Digestible protein }\end{array}$ & 12,08 & 12,36 & 10,89 & 11,27 \\
\hline $\begin{array}{l}\text { Relação kcal ED/gPD } \\
\text { Energy/protein digestible relation }\end{array}$ & 22,54 & 22,36 & 23,72 & 23,31 \\
\hline $\begin{array}{l}\text { Cálcio \% } \\
\text { Calcium }\end{array}$ & 0,80 & 0,79 & 0,80 & 0,79 \\
\hline $\begin{array}{l}\text { Fósforo total\% } \\
\text { Total phosphorus }\end{array}$ & 0,53 & 0,54 & 0,53 & 0,54 \\
\hline $\begin{array}{l}\text { Lisina } \%^{2} \\
\text { Lysine }\end{array}$ & 0,92 & 0,92 & 0,92 & 0,92 \\
\hline $\begin{array}{l}\text { Metionina } \%{ }^{2} \\
\text { Methionine }\end{array}$ & 0,58 & 0,59 & 0,58 & 0,59 \\
\hline
\end{tabular}

pré-desengorduramento em extrator tipo "soxhlet", para posterior moagem, em moinho tipo bola, seguindo procedimento feito por Scapinello (1993). A água e a gordura retiradas previamente às análises foram consideradas para correção dos valores subsequentes. Os resultados analíticos foram agrupados ao ganho de peso e usados para calcular a eficiência protéica e energética para carcaça, corrigida para composição química do corpo vazio ao início do experimento, por intermédio da análise de amostras compostas obtidas a partir de quatro láparos aos 45 dias de idade (Ferreira et al., 1996).

Os dados experimentais de desempenho e de carcaça foram submetidos à análise de variância e teste de médias a 5\% de significância (Student Newman Keulls) contidos no programa SAEG Sistema de Análises Estatísticas e Genéticas (UFV,
1997). O modelo estatístico para avaliação do rendimento produtivo geral foi :

$$
\mathrm{Y}_{\mathrm{ijk}}=\mu+\mathrm{A}_{\mathrm{i}}+\mathrm{F}_{\mathrm{j}}+\mathrm{AF}_{\mathrm{ij}}+\mathrm{e}_{\mathrm{ijk}}
$$

em que: $\mathrm{Y}_{\mathrm{ijk}}=$ valor observado das variáveis estudadas, relativo a cada unidade experimental $\mathrm{k}$, que recebeu a ração com nível de amido i e fonte de fibra j; $\mu$ = média geral da característica; $\mathrm{A}_{\mathrm{i}}=$ efeito do nível de amido ( $i=1$ e 2); $F_{j}=$ efeito da fonte de fibra ( $\mathrm{j}=1$ e 2); $\mathrm{AF}_{\mathrm{ij}}=$ efeito da interação nível de amido i e fonte de fibra $j ; E_{i j k}=$ erro aleatório associado a cada observação.

\section{Resultados e Discussão}

Os valores médios de desempenho e características de carcaça dos coelhos na fase de crescimento e terminação, alimentados com rações contendo dife- 
rentes níveis de amido e fontes de fibra, são apresentados na Tabela 3. Não foi verificado efeito significativo da interação entre nível de amido e fonte de fibra sobre os parâmetros avaliados $(\mathrm{p}<0,05)$, assim, os dados foram agrupados em médias para os fatores nível de amido e fonte de fibra isoladamente (Pimentel Gomes, 1987).

O peso vivo final, aos 85 dias de idade, não foi influenciado pelos tratamentos em estudo, no entanto, pode-se notar na Tabela 3, em valores absolutos, que o peso ao abate dos coelhos que receberam as rações com maiores níveis de amido (AA) foi levemente superior ao dos coelhos que receberam as rações com menores níveis de amido (BA), e os coelhos que receberam as rações contendo feno de alfafa (FA) também apresentaram leve superioridade em relação aos coelhos alimentados com as rações contendo casca de soja (CS). O ganho de peso vivo médio diário também não foi influenciado pelos tratamentos, demonstrando a mesma tendência do peso ao abate, em valores absolutos, uma pequena superioridade para o grupo alimentado com as rações contendo maiores níveis de amido (AA), enquanto para fonte de fibra nota-se pequena superioridade para o grupo das rações contendo feno de alfafa (FA). O ganho de peso está relacionado ao consumo de proteína digestível (PD), segundo De Blas et al. (1985) e Santomá et al. (1993), ingestão média de 10,6 g PD/d, torna-se necessário para permitir ganho de peso em torno de $33 \mathrm{~g} / \mathrm{d}$, justificando as tendências observadas sobre o peso vivo final e ganho em peso diário, pois a ingestão foi maior para as rações com $32 \%$ amido (AA - 10,91g PD/d) do que para as rações com 22\% amido (BA - 9,60g PD/d), e similar entre as rações com feno de alfafa (FA - 10,48 g PD/d) e casca de soja (CS - 10,39 g PD/d).

O consumo de ração médio diário não foi influenciado pelo nível de amido dietético, mas, foi observada influência significativa para fonte de fibra $(p<0,05)$, observando-se na Tabela 3, maior consumo médio diário para o grupo de coelhos alimentado com as rações à base de feno de alfafa (FA - 91,27 g/d) em relação ao grupo das rações à base de casca de soja (CS - 84,66 g/d), possivelmente, em função da qualidade da fibra, já que a maior lignificação dos constituintes da parede celular estimula o aumento da motilidade na região do ceco-cólon de coelhos, levando a uma maior taxa de passagem e consumo mais freqüente de alimento, além de um provável efeito sobre a palatabilidade das rações contendo feno de alfafa (Lleonart, 1980; Cheeke, 1987; De Blas, 1989).

Com relação aos índices de conversão alimentar, não houve influência do nível de amido, fonte de fibra ou interação entre eles, possivelmente, devido à manutenção da velocidade de crescimento ou ganho de peso em taxas similares entre os tratamentos dietéticos, com as pequenas variações nos valores de consumo de ração, refletindo em leves oscilações na conversão alimentar. Na Tabela 3, pode-se notar ligeira melhoria nos valores obtidos com coelhos alimentados com as rações contendo maiores níveis de amido (AA - 2,89), e, com os coelhos alimentados com as rações contendo casca de soja (CS - 2,88), sugerindo que estas rações proporcionaram um melhor aproveitamento dos princípios nutritivos, tanto a nível enzimático quanto microbiano, sendo que estas variações sobre o ganho de peso e o consumo caracterizam fenômeno fisiológico que traduz-se na otimização da eficiência alimentar (Carregal, 1976; Scapinello, 1984; Lopes, 1996; Arruda et al., 2000).

Comparativamente, Gidenne et al. (1991) e Blas et al. (1994), ao avaliarem o efeito de diferentes níveis de amido e fibra sobre o desempenho de coelhos, observaram que o ganho de peso vivo não foi influenciado pelas rações, mas, o consumo e a conversão alimentar foram maiores para a dieta fibrosa em relação à amilácea, resultados altamente relacionados com a eficiência energética proporcionada pelas rações, visto que, os coelhos são capazes de modificar a ingestão de alimento para sustentar a velocidade de crescimento, uma resposta compensatória reafirmada por Maertens (1992), para uma amplitude energética de 2465 a 3205 kcal ED/kg ração. Adicionalmente, De Blas et al. (1986) constataram, com níveis nutricionais similares ao deste estudo, que o ganho de peso e a conversão alimentar também não apresentaram diferenças estatísticas, concluindo que a eficiência de utilização dos nutrientes pode ser mantida pela regulação do consumo, para níveis de fibra indigestível situados entre 15 e $25 \%$ FDA, porém as respostas dentro desta amplitude podem ser variáveis, em função da qualidade dos componentes da parede celular, do tamanho de partícula e da relação amido/fibra na dieta (Cheeke, 1995). Tal inferência pode ser feita com segurança, pois, as recomendações de fibra com base no teor de FDA mostram-se como melhor indicador do equilíbrio digestivo e bom preditor do conteúdo energético de rações completas para coelhos (Lebas, 1991; Lebas,1992; e Lebas, 1999). 
Por outro lado, Falcão \& Cunha et al. (1996), constataram que rações contendo adição de gordura promoveram redução no consumo mais acentuadamente quando associado com volumoso mais lignificado, redução no ganho de peso, e assim, resultaram em índices de conversão alimentar maiores para estas rações, porém, Cervera et al. (1997) verificaram que o ganho de peso e a conversão alimentar foram otimizados quando se adicionou óleo na dieta, em virtude de um menor consumo e maior peso ao abate, devido a melhor utilização da energia da dieta. Portanto, as características qualitativas específicas das matérias-primas utilizadas na elaboração das rações possuem papel determinante no consumo e desempenho dos animais, em concordância com Ferreira (1989), Maertens (1992) e Carabaño (2000).

Com relação aos valores médios de rendimento de carcaça dos coelhos apresentados na Tabela 3, verificou-se influência do nível de amido dietético $(\mathrm{p}<0,05)$, constatando-se rendimento superior proporcionado pelas rações com menores níveis de amido (BA - 50,20 \%) em relação às rações com maiores níveis de amido (AA - 48,76 \%), sendo tal resposta associada a maior proporção média do peso do sistema digestivo em relação ao peso vivo $(\mathrm{p}<0,05)$ e maior rendimento médio em vísceras comestíveis $(p<0,05)$ para os animais alimentados com as rações de maior nível de amido (AA) em relação àqueles que receberam as rações de menor nível de amido (BA). Estes resultados tendem a refletir as variações nos índices de conversão alimentar, embora não significativos. É fato notório que o peso do sistema digestivo pode alterar o rendimento de carcaça, visto que este parâmetro baseia-se em uma proporção relativa ao peso vivo do animal, o que sugere menor rendimento de carcaça em função de maior peso do sistema digestivo, cuja inferência reside na taxa de renovação cecal e motilidade do ceco - cólon (Cheeke, 1995; Arruda, 2000).

Embora não tenha sido constatada influência da fonte de fibra sobre o rendimento de carcaça, verifica-se na Tabela 3, em valores absolutos, leve superioridade para os animais alimentados com feno de alfafa (FA) em relação àqueles alimentados com casca de soja (CS). Analogamente, pode-se sugerir a mesma tendência para efeito do peso relativo do sistema digestivo, pois o peso relativo do estômago e do ceco em relação ao peso vivo foi influenciado pela fonte de fibra $(p<0,05)$, sugerindo possível efeito dos constituintes da parede celular sobre o tempo de retenção da digesta e, conseqüentemente, sobre a cecotrofia, pois a casca de soja, por ser menos lignificada e potencialmente digestível, pode ter propiciado menor intensidade na dualidade de excreção cecal que o feno de alfafa, para um mesmo tamanho de partícula (Gidenne, 1996; Garcia et al., 1997; De Blas \& Wiseman, 1998).

Comparativamente, De Blas et al. (1986) constataram que a variação na relação amido:fibra dietética em níveis similares ao deste estudo, propiciou um aumento no peso do estômago com maior nível de fibra, em virtude de maior consumo (distenção gástrica) para compensar menor aporte energético, e maior quantidade de cecotrofos intactos no estômago dos coelhos. Já para rações contendo menores níveis de fibra, observaram maiores pesos de ceco, sugerindo que a taxa de renovação do conteúdo cecal é reduzida com rações possuindo baixos níveis de fibra. Os autores afirmam que apesar do acúmulo de material cecal permitir maior degradação da fração fibrosa da dieta, as disordens digestivas podem ter origem a partir deste efeito na peristalse intestinal, alterando o padrão fermentativo e equilíbrio osmótico intestinal de coelhos (Gidenne \& Lebas, 1984; Cheeke, 1987; De Blas, 1989; Gidenne, 1995).

Analogamente, Aboul-Ela et al. (1996) verificaram elevação na conversão alimentar e redução no rendimento de carcaça com rações mais fibrosas, sugerindo efeito sobre velocidade de trânsito da digesta. Já Garcia et al. (1993), ao avaliarem a substituição do amido por fibra de alta digestibilidade em rações contendo níveis nutricionais similares ao deste estudo, constataram rendimento de carcaça superior para a dieta mais fibrosa, em função de um menor peso relativo do sistema digestivo. Fraga et al. (1991), também verificaram diferenças no peso relativo do sistema digestivo ao fornecerem feno de alfafa como alimento - referência, observando médias superiores com volumosos menos lignificados e superiores para estômago e inferior para o ceco com volumosos mais lignificados em virtude da qualidade da fibra. Assim, rações menos lignificadas propiciam maior tempo de retenção, enquanto rações mais lignificadas uma maior velocidade de trânsito, resultando em diferenças no peso visceral e eficiência alimentar, ou seja, variações na degradabilidade e padrão fermentativo cecal (Gidenne, 1987, 1995, 1996).

Com relação às características qualitativas da carcaça dos coelhos, verificou-se neste estudo que os níveis de matéria seca, de proteína, de gordura e de 
Tabela 3 - Desempenho, características quantitativas e qualitativas da carcaça de coelhos em crescimento submetidos às rações experimentais

Table 3 - Performance, qualitative and quantitative characteristics of rabbit carcass in growth phase fed experimental diets

\begin{tabular}{|c|c|c|c|c|c|c|}
\hline \multirow{4}{*}{$\begin{array}{l}\text { Parâmetros } \\
\text { Parameters }\end{array}$} & \multicolumn{4}{|c|}{$\begin{array}{c}\text { Tratamentos } \\
\text { Treatments }\end{array}$} & \multirow{4}{*}{$\begin{array}{l}\text { Média } \\
\text { Mean }\end{array}$} & \multirow{4}{*}{$\mathrm{CV}(\%)$} \\
\hline & \multirow{2}{*}{\multicolumn{2}{|c|}{$\begin{array}{c}\text { Nível de amido } \\
\text { Starch level }\end{array}$}} & \multirow{2}{*}{\multicolumn{2}{|c|}{$\begin{array}{c}\text { Fonte de fibra } \\
\text { Fibersource }\end{array}$}} & & \\
\hline & & & & & & \\
\hline & AA 1,2 & $\mathrm{BA}^{3,4}$ & $\mathrm{FA}^{1,3}$ & $\mathrm{CS}^{2,4}$ & & \\
\hline \multirow{2}{*}{$\begin{array}{l}\text { Peso vivo inicial (g) } \\
\text { Initial live weight }\end{array}$} & 960,25 & 991,75 & 967,00 & 985,00 & 976,00 & 7,30 \\
\hline & & & & & & \\
\hline Peso vivo final (g) & 2196,5 & 2170,2 & 2190,7 & 2176,0 & 2183,4 & 6,95 \\
\hline \multicolumn{7}{|l|}{ Final live weight } \\
\hline Ganho de peso (g/d) & 30,90 & 29,46 & 30,59 & 29,77 & 30,18 & 13,15 \\
\hline \multicolumn{7}{|l|}{ Daily weight gain } \\
\hline Consumo ração (g/d) & 89,30 & 86,64 & $91,27^{\mathrm{e}}$ & $84,66^{f}$ & 87,97 & 9,16 \\
\hline \multicolumn{7}{|l|}{ Daily feed intake } \\
\hline $\begin{array}{l}\text { Conversão alimentar } \\
\text { Feed / gain }\end{array}$ & 2,89 & 2,98 & 3,01 & 2,88 & 2,94 & 11,36 \\
\hline Rend. carcaça (\%) & $48,76^{\mathrm{b}}$ & $50,20^{\mathrm{a}}$ & 49,68 & 49,28 & 49,48 & 3,27 \\
\hline \multicolumn{7}{|l|}{ Carcass yield } \\
\hline Vísceras comestíveis (\%pv) & $3,84^{\mathrm{a}}$ & $3,21^{b}$ & 3,51 & 3,54 & 3,53 & 11,32 \\
\hline \multicolumn{7}{|l|}{ Liver and heart } \\
\hline Sist. digestivo (\%pv) & $18,39^{\mathrm{a}}$ & $17,26^{\mathrm{b}}$ & 17,45 & 18,20 & 17,83 & 9,71 \\
\hline \multicolumn{7}{|l|}{ Visceral organs } \\
\hline \multicolumn{7}{|l|}{ Stomach weight } \\
\hline Peso cecal (\%pv) & $7,31^{\mathrm{a}}$ & $6,38^{\mathrm{a}}$ & $6,04^{f}$ & $7,65^{\mathrm{e}}$ & 6,84 & 14,91 \\
\hline \multicolumn{7}{|l|}{ Caecal weight } \\
\hline MS carcaça (\%) & $33,65^{b}$ & $35,87^{\mathrm{a}}$ & 34,60 & 34,93 & 34,76 & 2,97 \\
\hline $\begin{array}{l}\text { Carcass dry matter } \\
\text { Gordura (\%MS) }\end{array}$ & $23,90^{\mathrm{b}}$ & $29,97^{\mathrm{a}}$ & 26,62 & 27,25 & 26,94 & 10,19 \\
\hline $\begin{array}{l}\text { Carcass fat } \\
\text { Proteína (\%MS) } \\
\text { Carcass protein }\end{array}$ & $62,36^{\mathrm{a}}$ & $55,60^{\mathrm{b}}$ & 58,31 & 59,64 & 58,98 & 6,09 \\
\hline Energia (kcal/kg MS) & $6380,9^{b}$ & $6442,5^{\mathrm{a}}$ & 6425,4 & 6398,1 & 6411,7 & 1,21 \\
\hline \multicolumn{7}{|l|}{ Carcass energy } \\
\hline Efic. protéica (\%) & $56,38^{\mathrm{a}}$ & $52,74^{b}$ & 53,21 & 55,91 & 54,56 & 9,94 \\
\hline \multicolumn{7}{|l|}{ Proteic efficiency } \\
\hline Efic. energética (\%) & $30,04^{\mathrm{a}}$ & $28,10^{b}$ & 28,35 & 29,80 & 29,07 & 8,93 \\
\hline \multicolumn{7}{|l|}{ Energyefficiency } \\
\hline $\begin{array}{l}\text { Médias seguidas de letr } \\
\text { followed by differents lette }\end{array}$ & $\begin{array}{l}\text { entes são e } \\
\text { atistically diffe }\end{array}$ & $\begin{array}{l}\text { camente dif } \\
\text { or the SNK } t\end{array}$ & $\begin{array}{l}\text { s pelo teste } \\
\text { 05] for starc }\end{array}$ & $\begin{array}{l}(\mathrm{P}<0,05) \mathrm{p} \\
\text { factor). }\end{array}$ & ator nível c & do (Means \\
\hline $\begin{array}{l}\text { Médias seguidas de lett } \\
\text { followed by differents lette }\end{array}$ & $\begin{array}{l}\text { rentes são e } \\
\text { atistically diffe }\end{array}$ & $\begin{array}{l}\text { icamente di } \\
\text { or the SNK } t\end{array}$ & $\begin{array}{l}\text { es pelo test } \\
\text { 05] for fiber }\end{array}$ & $\begin{array}{l}(P<0,05) \\
\text { ctor })\end{array}$ & fator fonte & ra (Means \\
\hline $\begin{array}{ll}1,2,3,4 & \text { Rações experimentais } \\
5 & \text { Interação não-signficati }\end{array}$ & belas 1 e 2) & $\begin{array}{l}\text { imental diets } \\
n \text { ). }\end{array}$ & ables 1 and & & & \\
\hline
\end{tabular}

energia foram significativos para nível de amido dietético $(\mathrm{p}<0,05)$. Na Tabela 3, pode-se notar que os teores médios de matéria seca, gordura e energia do corpo vazio foram superiores nos coelhos alimentados com as rações contendo menores níveis de amido (BA - 35,87\%, 29,97\% e 6442,50 kcal/kg, respectivamente) em relação aqueles com as rações contendo maiores níveis de amido (AA - 33,65\%, 23,90\% e $6380,90 \mathrm{kcal} / \mathrm{kg}$, respectivamente), mas, o teor de proteína foi maior nos animais alimentados com a dieta de maior nível de amido (AA - 62,36\%) em relação aos da dieta de menor nível de amido (BA 55,60\%). Considerando os melhores índices de conversão alimentar com as rações contendo maior nível amido (AA), e origem da energia suprida pelas rações (Tabela 1), sugere-se que houve capacidade diferenciada na utilização da energia e proteína dietéticas, promovendo maior deposição de gordura e energia, e, menor de água e proteína, nos coelhos submetidos às rações com menores níveis de amido (BA). Tal influência confirma-se pelo efeito do nível de amido sobre a eficiência na utilização ou deposição 
de proteína ( $\mathrm{p}<0,05)$ e de energia $(\mathrm{p}<0,05)$ na carcaça, pois na Tabela 3 podem-se observar valores superiores para os animais submetidos às rações com maiores níveis de amido (AA - 56,38 e 30,04\%, respectivamente) em relação aos das rações de baixo amido (BA - 52,74 e 28,10\%, respectivamente).

Com relação à fonte de fibra, não foi observada influência sobre as características qualitativas da carcaça dos coelhos, no entanto, na Tabela 3, em valores absolutos, pode-se notar uma leve superioridade nos níveis de proteína e gordura da carcaça de animais submetidos às rações contendo casca de soja (CS) em relação às rações contendo feno de alfafa (FA), sendo a mesma tendência observada sobre a retenção energética e protéica nos animais submetidos a estas rações experimentais.

Comparativamente aos resultados observados neste estudo, Ferreira et al. (1996), ao avaliarem substituição da fonte de fibra dietética, observaram que ao fornecer um volumoso mais lignificado na dieta, verificaram piora no índice de conversão alimentar, e um aumento no teor de gordura na carcaça dos coelhos, mas o teor de matéria seca, proteína e energia não variaram significativamente, sendo sugerido que o consumo de energia superior ao de proteína digestível, pode ter limitado o desenvolvimento muscular e elevado a deposição de gordura corporal. No entanto, ao avaliarem a substituição do amido por fibra de alta degradabilidade em rações de coelhos em crescimento, Garcia et al. (1993) constataram redução na eficiência alimentar, no teor de gordura e energia da carcaça, porém aumento no teor de proteína, associado a um peso de abate mais tardio dos animais submetidos à dieta mais fibrosa. Por outro lado, Fernandez \& Fraga (1996), ao avaliarem o efeito da inclusão de óleo de soja combinado ou não com soja integral para coelhos em crescimento, verificaram elevação nos níveis de matéria seca e de gordura da carcaça com a elevação do teor de extrato etéreo dietético, enquanto os níveis de proteína e energia não variaram significativamente.

Analogamente, Lebas et al. (1986), Ouhayoun et al. (1986) e Perez de Ayala et al. (1991) relatam que, ao aumentar o nível de fibra de potencialmente digestível na dieta, ocorre redução no rendimento de carcaça de coelhos pelo aumento no peso relativo do sistema digestivo, mas o peso relativo de vísceras comestíveis, como o fígado, ainda não permite conclusão definitiva, devido à variabilidade proporcionada pelo desenvolvimento alométrico. Na Tabela 3 pode-se verificar que as carcaças dos coelhos alimentados com rações contendo fibra e óleo em substituição ao milho apresentaram menores teores de água e maiores de gordura, em concordância com Fraga et al. (1983) e Patridge et al. (1989).

O aumento no nível de fibra dilui o teor energético da dieta, e embora possa ser corrigido parcialmente pela inclusão de óleos ou gorduras, parece existir uma influência da proporção lipídios com carboidratos totais, sobre a quantidade de tecido adiposo escapular, peri-renal e subcutâneo, o que pode resultar em diferenças na mensuração dos teores de matéria seca, gordura, proteína e energia nas carcaças ou corpo vazio, com aditividade das diferentes técnicas ou padrões de evisceração e limpeza da carcaça à quente (Parigi-Bini et al.,1990; Scapinello, 1993; Cheeke, 1995; Kulkarni et al., 1995; Ferreira et al., 1996; De Blas \& Wiseman, 1998). Por outro lado, o teor de energia da carcaça tende a ser maior quando os animais são alimentados com rações contendo relação energia/proteína digestível mais elevada, que, segundo Fraga et al. (1983), pode proporcionar maior deposição de gordura corporal e pode estar relacionado com o aumento no teor de matéria seca e redução da proteína da carcaça, fato observado também por Spreadbury (1978). Assim, o nível e o tipo de fibra podem influenciar a relação energia/ proteína digestível, os teores de proteína e energia na carcaça e eficiência de retenção de nutrientes, também sugerido por Gomes (1996).

No presente trabalho, não foram observados sinais de morbidade, nem taxas de mortalidade nos animais submetidos às rações experimentais, o que se deve aos níveis mínimos de fibra "indigestível ou de lastro" proporcionados pela combinação do feno de alfafa ou casca de soja com sabugo de milho, e, possivelmente, pela eficiente utilização dos níveis de amido proporcionados pela inclusão de milho grão nas rações. Além disso, a relação kcal ED/g PD situou-se em torno de 22 a 24 (Tabela 2), que, segundo De Blas (1989), é a amplitude que permite obter os menores índices de mortalidade e os melhores desempenhos dos coelhos. Resultados similares sobre a sanidade do plantel experimental também foram observados por Arruda et al. (2000).

Comparativamente, De Blas et.al. (1986) constataram com níveis nutricionais similares ao deste estudo, notaram uma diferença de $10 \%$ na taxa de mortalidade devido à distúrbios digestivos nos animais submetidos às rações ricas em amido. Blas et al. 
(1994), observaram ótimo desempenho dos animais, porém, houve maior susceptibilidade a diarréias com as rações amiláceas, sendo a taxa de mortalidade em torno de $8 \%$, enquanto a dieta com baixo teor de amido propiciou valor médio de $4 \%$. Porém, Gidenne et al. (1991), ao avaliarem a adaptação digestiva de coelhos em crescimento, alimentados com níveis de fibra e amido próximos ao deste ensaio, não observaram mortalidade nem morbidade nos animais em experimentação.

Analogamente, Garcia et al. (1993), ao avaliarem a substituição do amido por fibra de alta degradabilidade em rações para coelhos, sugerem que a inclusão de fibra altamente digestível pode atuar como agente permissivo à distúrbios digestivos, o que se traduz pela interação hipomotilidade hiperfermentação cecal, similarmente ao excesso de amido, ao verificarem taxas de mortalidade médias de 4,7 vs. 9,0\% para menor e maior inclusão de fibra de alta degradabilidade. Aboul-Ela et al. (1996), ao avaliarem diferentes níveis de fibra em rações para coelhos, verificaram que a taxa de mortalidade foi similar para ambos os níveis de fibra, cerca de 6,6\%, porém, tais níveis de fibra foram os que propiciaram menor incidência de diarréias. Todavia, Fraga et al. (1991), ao avaliarem o efeito de diferentes fontes de fibra na alimentação de coelhos, não constataram morbidade nem mortalidade com os animais durante o período experimental. Portanto, a casca de soja pode ser bem utilizada por coelhos em crescimento, assim como altos níveis de amido dietético, porém, respeitando-se as recomendações nutricionais preconizadas para esta espécie.

\section{Conclusões}

As rações contendo diferentes níveis de amido e fontes de fibra não influenciaram o desempenho dos coelhos em crescimento, e o rendimento de carcaça foi melhor com as rações contendo menores níveis de amido e similar para as fontes de fibra. As rações contendo maiores níveis de amido ou com casca de soja propiciaram maiores níveis de proteína e melhor eficiência protéica e energética na carcaça de coelhos terminados.

\section{Agradecimento}

À Santista Alimentos SA - Divisão SAMRIG, pela doação da casca de soja usada neste estudo.

\section{Literatura Citada}

ABOUL-ELA, S.; ABDEL-RAHMAN, G.A.; ALI, F.A. et. al. Practical recommendations on minimum and maximum fiber levels in rabbit diets. In: WORLD RABBIT CONGRESS, 6., 1996, Tolouse. Proceedings... Tolouse: AFC - INRA, 1996. v.1, p. 67-72.

ASSOCIATION OF OFFICIAL ANALYTICAL CHEMISTS AOAC. Official methods of analysis. 15.ed., Virginia: Arlington, 1990. 1117p.

ARRUDA, A.M.V. Digestibilidade, desempenho e produção de ácidos graxos voláteis de coelhos alimentados com rações contendo diferentes níveis de amido. Jaboticabal, SP: UNESP, 1997, 96p. Dissertação (Mestrado em Zootecnia) - Faculdade de Ciências Agrárias e Veterinárias, Campus de Jaboticabal/Universidade Estadual Paulista, 1997.

ARRUDA, A.M.V.; CARREGAL, R.D.; FERREIRA, R.G. Desempenho produtivo e atividade microbiana cecal de coelhos alimentados com rações contendo diferentes níveis de amido. Revista Brasileira de Zootecnia, v.29, n.3, p.762768, 2000.

BLAS, E.; CERVERA, C.; FERNANDEZ-CARMONA, J. Effect of two diets with varied starch and fiber levels on the performance of 4-7 weeks old rabbits. World Rabbit Science, v.2, n.4, p.117-121, 1994.

CARABAÑO, R. Sistemas de producción de conejos en condiciones intensivas. In: REUNIÃO ANUAL DA SOCIEDADE BRASILEIRA DE ZOOTECNIA, 37., 2000, Viçosa, MG. Anais...Viçosa: Sociedade Brasileira de Zootecnia, 2000. p.17-38.

CARREGAL, R.D. Efeito da idade e de diferentes níveis de fibra bruta sobre a digestibilidade de nutrientes de rações de coelhos. Piracicaba: Escola Superior de Agricultura "Luís de Queiroz”, 1976. 70p. Dissertação (Mestrado em Zootecnia) Escola Superior de Agricultura "Luis de Queiroz”, 1976.

CERVERA, C.; BLAS, E.; FERNANDEZ-CARMONA, J. Growth of rabbits under different environmental temperatures using high fat diets. World Rabbit Science, v.5, n.2, p.7175, 1997.

CHEEKE, P.R. Rabbit feeding and nutrition. Oregon: Academic Press, 1987. 380p.

CHEEKE, P.R. Alimentación y nutrición del conejo. Zaragoza: Acribia, 1995. 429p.

DE BLAS, J.C.; FRAGA, M.J.; RODRIGUEZ, J.M. Units for feed evaluation and requirements for commercial growth rabbits. Journal of Animal Science, v.60, n.1, p.10211027, 1985.

DE BLAS, J.C.; SANTOMÁ, G.; CARABAÑO, R. et.al. Fiber and starch levels in fattening rabbit diets. Journal of Animal Science, v.63, n.3, p.1897-1904, 1986.

DE BLAS, C. Alimentación del conejo. Madrid: Ed. MundiPrensa, 1989. 175p.

DE BLAS, C.; WISEMAN, J. The nutrition of the rabbit. Cambridge: University Press - CAB International, 1998. 344p.

FALCÃO e CUNHA, L.; BENGALA-FREIRE, J.P.; GONÇALVES, A. Effect of fat level and fiber nature on performance, digestibility, nitrogen balance and digestive organs in growing rabbits. In: WORLD RABBIT CONGRESS, 6., 1996, Tolouse. Proceedings... Tolouse: AFC - INRA, 1996. v.1, p.157-164.

FERNANDEZ, C.; FRAGA, M.J. The effect of dietary fat inclusion on growth, carcass characteristics and chemical composition of rabbits. Journal of Animal Science, v.74, n.1, p.2088-2094, 1996. 
FERREIRA, W.M. Matérias-primas utilizadas na formulação de rações para coelhos: restrições e alternativas. Informativo Agropecuário, v.14, n.159, p.16-24, 1989.

FERREIRA, W.M.; FRAGA, M.J.; CARABAÑO, R. Inclusion of grape pomace in substitution for alfafa hay in diets for growing rabbits. Animal Science, v.63, n.1, p.167-174, 1996.

FRAGA, M.J.; DE BLAS, J.C.; PEREZ, E. et. al. Effect of diet on chemical composition of rabbits slaughtered at fixed body weights. Journal of Animal Science, v.56, n.4, p.1097-1103, 1983.

FRAGA, M.J.; PÉREZ DE AYALA, P.; CARABAÑO, R. et. al. Effect of type of fiber on the rate of passage and on the contribution of soft feces to nutrient intake of finishing rabbits. Journal of Animal Science, v.69, n.4, p.1566-1574, 1991.

GARCIA, G.; GALVEZ, J.F.; DE BLAS, J.C. Effect of substitution of sugarbeet pulp in diets for finishing rabbits on growth performance and nitrogen efficiency. Journal of Animal Science, v.71, p.1823-1830, 1993.

GARCIA, J.; VILLAMIDE, M.J.; DE BLAS, J.C. Energy, protein and fiber digestibility of soybean hulls for rabbits. World Rabbit Science, v.5, n.3, p.111-115, 1997.

GIDENNE, T.; LEBAS, F. Evolution circadienne du contenu digestif chez le lapin en croissance - relation avec la caecotrophie. In: WORLD RABBIT CONGRESS, 3., 1984, Roma. Proceedings... Roma: FAO - INRA, 1984. p.494-501.

GIDENNE, T. Influence de la teneur en lignines des aliments sur la composition des digesta et la production de caecotrophes chez le laperau. Annales de Zootechnie, v.36, n.1, p.85-89, 1987.

GIDENNE, T.; SCALABRINI, F.; MARCHAIS, C. Adaptation digestive du lapin à la teneur en constituants parietáux du régime. Annales de Zootechnie, v.40, n.2, p.73-84, 1991.

GIDENNE, T. Apports de fibres et d'amidon : consequences digestives chez le lapin en croissance. In: JORNADA TÉCNICA SOBRE CUNICULTURA, 7., 1995, Barcelona. EXPOAVIGA'95... Barcelona, 1995. p.805-825.

GIDENNE,T. Nutritional and ontogenic factors affecting rabbit caeco-colic digestive phisiology. In: WORLD RABBIT CONGRESS, 6., 1996, Tolouse. Invited Papers...Tolouse, AFC - INRA, 1996. p.13-28.

GOMES, A.V.C. Utilização de diferentes fontes de fibra na alimentação de coelhos en crescimento. Belo Horizonte: Universidade Federal de Minas Gerais, 1996. 129p. Tese (Doutorado em Zootecnia) - Universidade Federal de Minas Gerais, 1996.

INSTITUT NATIONAL DE LA RECHERCHE AGRONOMIQUE - INRA. L'alimentation des animaux monogatriques: porc, lapin e volailles. Tolouse, Publiè du Ministère Français, 1984. p.77-84.

KULKARNI, V.V.; GUPTA, K.; BHATT, R. et. al. Growth, carcass traits and meat composition of broiler rabbits. Indian Journal of Animal Science, v.65, n.5, p.599-601, 1995.

LANG, J. The nutrition of the commercial rabbit. Part 1 Physiology, digestibility and nutrient requirements. Nutrition Abstracts Reviews, v.51, n.4, p.197-221, 1981.

LEBAS, F.; COUDERT, P.; ROUVIER, A. et al. El conejo: cria y patologia. Organización de las Nacioenes Unidas para la Agricultura y la Alimentación. Roma, Colecciones FAO, 1986. 278p.

LEBAS, F. Alimentación y funcionamiento digestivo del conejo. Cuniculture, v.16, n.92, p.224-228, 1991.

LEBAS, F. La alimentación practica del conejo de engorde. Boletim Cuniculture, v.1, n.59, p.34-43, 1992.

LEBAS, F. Recomendações alimentares: alimentação dos coelhos. In: INRA - Alimentação dos animais monogástricos: suínos, coelhos e aves. 2.ed. São Paulo: Roca, 1999. p.76-84.

LLEONART, F.R. Tratado de Cunicultura. Anatomía y fisiología del aparato digestivo. Barcelona: Real Escuela Oficial y Superior de Avicultura, 1980. v.1, p.61-84.

LOPES, D.C. Avaliação de alimentos e exigência de energia digestível de coelhos da raça Nova Zelândia Branco em crescimento e reprodução. Viçosa, MG: Universidade Federal de Viçosa, 1996. 114p. Tese (Doutorado em Zootecnia) Universidade Federal de Viçosa, 1996.

MAERTENS, L. Rabbit nutrition and feeding - A review of some recent developments. Journal of Applied Rabbit Research, v.15, n.1, p.889-915, 1992.

NATIONAL RESEARCH COUNCIL - NRC. Nutrients requirements of rabbits. Washington, D.C.: National Academy Press, 1977. 30p.

OUHAYOUN, J.; LEBAS, F.; DELMAS, D. La croissance et la composition corporelle du lapin : influence des facteurs alimentaires. Cuni-Sciences, v.3, n.2, p.7-21, 1986.

PARIGI-BINI, R.; XICCATO, G.; CINETTO, M. Influenza del contenuto di amido alimentare sulla produtivita, sulla digeribilita e sula composizione corporea di conigli in accrescimento. Zootechnical Nutrition Animal, v.16, n.1, p.271-282, 1990.

PATRIDGE, G.G.; GARTHWAITE, P.H.; FINDLAY, M. Protein and energy retention by growing rabbits offered diets with increasing proportions of fiber. Journal of Agriculture Science, v.112, n.1, p.171-178, 1989.

PEREZ DE AYALA, P.; FRAGA, M.J.; CARACBAÑO, R. et al. Effect of fiber source on diet digestibility and growth in fattening rabbits. Journal of Applied Rabbit Research, v.14, n.1, p.159-164, 1991.

PIMENTEL GOMES, F.P. Curso de estatística experimental. Piracicaba: Escola Superior de Agricultura “Luís de Queiroz”, 1987. 467p.

RHODIMET - Rhône Poulenc Animal Nutrition, Feed formulation guide, Recommendations for feed formulation - Rabbits. 6.ed., 1993. p.24.

SCAPINELLO, C. Utilização do feno de rama de mandioca na alimentação de coelhos em crescimento. Lavras: Universidade Federal deLavras, 1984. 71p. Dissertação(Mestrado em Zootecnia) - Universidade Federal de Lavras, 1984.

SCAPINELLO, C. Níveis de proteína bruta e de energia digestível e exigências de lisina e de metionina + cistina para coelhos da raça Nova Zelândia Branco em crescimento. Viçosa, MG: Universidade Federal de Viçosa, 1993. 215p. Tese (Doutorado em Zootecnia) - Universidade Federal de Viçosa, 1993.

SILVA, D.J. Análise de alimentos: métodos químicos e biológicos. Viçosa, MG: Universidade Federal de Viçosa, 1990. 166p.

SPREADBURY, D.; DAVIDSON, J. A study of the need fiber by the growing New Zealand White rabbit. Journal of Science Food and Agriculture, v.29, n.7, p.640-648, 1978.

UNIVERSIDADE FEDERAL DE VIÇOSA - UFV. SAEG Sistemas de Análises Estatísticas e Genéticas. Versão 7.1. Viçosa, MG, 1997. 150p. (Manual do usuário)

Van SOEST, P.J., ROBERTSON, J.B., LEWIS, B.A. Methods for dietary fiber, neutral detergent fiber, and nonstarch polyssacharides in relation to animal nutrition. Journal of Dairy Science, v.74, n.10, p.3583-3597, 1991.

Van SOEST, P.J. Nutritional ecology of the ruminant. 2.ed. Cornell: Cornell University Press, 1994. 476p.

Recebido em: 29/11/01

Aceito em: 20/11/02 